\title{
Deoxyribonucleic Acid and High Temperature Sensitivity in Wheat
}

\author{
R.S. Utkhede ${ }^{1}$ and H.K. Jain \\ Division of Genetics, IARI, N. Delhi 12, India
}

Received January 9, 1973

Experimentally, there have been few attempts to analyse the polyploids from the point of view of adaptation. Most studies have been restricted to the morphological and cytological effects of chromosome doubling. The present cytochemical studies were planned to investigate the role of increased DNA content and the sensitivity of their chromosomes to conditions of high temperature in the cells $o_{1}$ polyploids in relation to adaptability in wheat species.

\section{Materials and methods}

Microautoradiographic technique was employed to study the synthesis of deoxyribonucleic acid (DNA) in root-tip cells of varieties of different species. One variety from each species was selected.

Species

1) Triticum monococcum

2) Triticum dicoccum

3) Triticum durum

4) Triticum aestivum

a) DNA synthesis: The seeds of all the four varieties were germinated in an incubator at $23^{\circ} \mathrm{C}$. When the root-tips were about $1.0 \mathrm{~cm}$ long, they were transferred to a petridish containing a solution of tritiated thymidine $(2 \mu \mathrm{c} / \mathrm{ml}$ specific activity- $3 \mathrm{c} / \mathrm{mM}$ ). The roots were kept in the radioactive solution for ten hours. They were then thoroughly washed and transferred to water for two hours and subsequently to 0.05 per cent colchicine solution for three hours before fixation. Root-tips were fixed in a mixture of absolute alcohol and acetic acid ( $3: 1)$ for 15 minutes and stored in 95 per cent alcohol in a refrigerator. They were hydrolysed in N.HCL for 14 minutes at $60^{\circ} \mathrm{C}$ and stained with the Feulgen reaction and squashed in 0.05 per cent acetocarmine on gelatinised slides $(0.5$ per cent aqueous solution of gelatin). The coverslips were removed by putting the slides in an inverted position on dry ice for 1-1 1/2 minutes. The slides were stored in 95 per cent alcohol and were passed through a descending alcohol series $95 \% \rightarrow 75 \% \rightarrow$ $50 \% \rightarrow 25 \% \rightarrow$ distilled water, before putting the film on. The stripping film (AR

1 Present address: Dr. R.S. Utkhede, Maize Breeder, Agricultural Research Institute, Ukiriguru, P. O. Box 1433, Mwanza, Tanzania. 
10) was applied following the standard technique (Darlington and LaCour 1962).

The autoradiographs were developed after 30 days of exposure in the dark. A quantitative study of incorporation of thymidine was made by counting the silver grains in 20 cells of each of the varieties.

b) Temperature treatment: The procedure for the temperature treatment and its evaluation have already been described in an earlier communication (Utkhede and Jain 1970).

Table 1. Number of grains per cell in root-tips of different species

(Thymidine $2 \mu \mathrm{c} / \mathrm{ml}$ for 10 hours)

\begin{tabular}{c|c|c|c|c}
\hline Cell no. & $\begin{array}{c}\text { T. monococcum } \\
\text { (E 4371) }\end{array}$ & $\begin{array}{c}\text { T. dicoccum } \\
\text { (E 4325) }\end{array}$ & $\begin{array}{c}\text { T. durum } \\
\text { (H. 84) }\end{array}$ & $\begin{array}{c}\text { T. aestivum } \\
\text { (E 4642) }\end{array}$ \\
\hline 1 & 200 & 442 & 386 & 536 \\
2 & 252 & 407 & 604 & 712 \\
3 & 200 & 466 & 385 & 641 \\
4 & 236 & 430 & 367 & 533 \\
5 & 244 & 416 & 421 & 514 \\
6 & 224 & 504 & 310 & 448 \\
7 & 216 & 222 & 383 & 558 \\
8 & 214 & 385 & 522 & 750 \\
9 & 246 & 430 & 458 & 400 \\
10 & 268 & 433 & 472 & 418 \\
11 & 218 & 470 & 333 & 598 \\
12 & 248 & 365 & 532 & 574 \\
13 & 208 & 341 & 377 & 398 \\
14 & 219 & 464 & 477 & 410 \\
15 & 195 & 304 & 483 & 455 \\
16 & 210 & 321 & 339 & 413 \\
17 & 214 & 260 & 408 & 362 \\
18 & 212 & 400 & 318 & 494 \\
19 & 198 & 368 & 476 & 468 \\
20 & 238 & 428 & 468 & 588 \\
\hline Total & 4460 & 7855 & 8519 & 10270 \\
Mean & 223.00 & 392.75 & 425.95 & 513.50 \\
Ratio & 1.00 & 1.76 & 1.91 & 2.30 \\
\hline C. & & &
\end{tabular}

C.D. at $5 \%$ level—48.16

Interspecific comparison:

$T$. monococcum $<T$, dicoccum $=T$. durum $<T$. aestivum.

\section{Results}

a) DNA synthesis: The variation in chromosome number in the different species is obviously expected to affect the amount of DNA in the nucleus. An attempt has been made to estimate this variation in the amount of DNA in the nuclei of some of the varieties belonging to different species. A large number of 
cells in the autoradiographs, prepared from the root-tips grown in tritiated thymidine, were found to be labelled. These labelled cells, showed considerable variation in grain formation. Thus some of the cells were so heavily labelled that no counting of grains was possible. Some other cells, however, were found to be well labelled and the formation of grains in them was such that counting was possible. It is these well labelled cells, that were used for grain counts. The extreme types of cells, which included those heavily labelled and others with relatively few grains, were excluded from the observations. Observations recorded on grain formation are presented in Table 1. A critical examination of the data clearly indicates that the diploid, tetraploid and hexaploid varieties show an increase in the amount of DNA in that order but the increase is not proportional to the number of chromosomes in these species. However, the total length of the chromosomes in the A, B and $\mathrm{D}$ genomes is known to vary, and for this reason the DNA content of the nuclei in the different species cannot be expected to show a ratio, proportionate to the chromosome number. The total length of chromatin material in the species T. monococcum, T. dicoccum, and T. aestivum has been reported to be in the proportion of $1: 1.5: 2.0$ (Pai et al. 1961)

An ' $F$ ' test was performed to compare the interspecific variation in grain count. The analysis showed that while there were significant differences in grain formation at different levels of ploidy, the two tetraploid species, $T$. dicoccum and $T$. durum, did not differ significantly.

b) Temperature sensitivity of chromosomes: Temperature is perhaps the most impotant component of natural environment, and it may be supposed that the ability of wheat plant to withstand extremes of temperature has been one of the most important character, leading to its wider adaptability and cultivation throughout the world. Degeneration of chromatin material was found to be one of the most striking effects of high temperature treatment and could be observed in a large number of pollen mother cells. It will be seen from the Table 2 that the number of pollen mother cells showing degenerations, increases with the increasing duration of treatment. The observations showed that the diploid species $T$. monococcum is the most sensitive followed by $T$. durum, $T$. dicoccum and $T$. aestivum in that order.

\section{Discussion}

The fact that in wheat the increasing level of polyploidy has been found to be associated with greater tolerance of the chromosomes to high temperature, and of the plants of a wider range of environmental conditions, may suggest that chromosome doubling per se has a role in this regard. One possible explanation for the greater environmental stability of the polyploid wheat species may be the buffering action of the additional genes present. This dosage effect can be expected to vary with variation in the amount of DNA in the diploid and polyploid species. The ratio of DNA in the root-tip cells of different species as expected showed that the amount of DNA increased with increasing level of ploidy. Nishikawa and Furuta (1969) also found that the amount of DNA content increased with the level of 
ploidy in wheat species. It should also be emphasized here that the DNA estimates made by the autoradiographic technique in the present study correspond well with similar estimates made by absorption microspectrophotometry technique employed by Rees $(1963,1965)$ and by Upadhya and Swaminathan (1963) in determining the amount of DNA in root tip cells of the four wheat species, considered here.

A comparative analysis of the DNA estimates in the present study and those by earlier authors is represented in Table 3, which depicts that although the ratio of DNA in the cells of $T$. monococcum, $T$. dicoccum, $T$. durum and $T$. aestivum obtained in these different studies differ, they all agree in showing the same trend.

Table 2. Percentage of pollen mother cells with degeneration of chromatin material in different species

\begin{tabular}{c|c|c|c|c}
\hline $\begin{array}{c}\text { Duration of } \\
\text { treatment in } \\
\text { hours }\left(38^{\circ} \mathrm{C}\right)\end{array}$ & $\begin{array}{c}T . \\
\text { monococcum } \\
(\mathrm{E} \mathrm{4371)}\end{array}$ & $\begin{array}{c}T . \\
\text { dicoccum } \\
\text { (E 4325) }\end{array}$ & $\begin{array}{c}T . \\
\text { durum } \\
(\mathrm{H} .84)\end{array}$ & $\begin{array}{c}T . \\
\text { aestivum } \\
\text { (E 4642) }\end{array}$ \\
\hline 12 & 23.80 & 8.80 & 4.80 & 0.20 \\
24 & 40.00 & 9.80 & 18.40 & 1.80 \\
48 & 73.60 & 24.00 & 33.60 & 12.40 \\
72 & - & 37.00 & 43.60 & 19.80 \\
\hline $\begin{array}{l}\text { Overall } \\
\text { species mean }\end{array}$ & 45.80 & 19.90 & 25.10 & 8.55 \\
$\begin{array}{c}\text { Relative proportion } \\
\text { of affected cells }\end{array}$ & 5.35 & 2.32 & 2.93 & 1.00 \\
\hline
\end{tabular}

Table 3. Proportion of DNA in root-tip cells of different species

\begin{tabular}{l|c|c|c|c}
\hline \hline & $\begin{array}{c}T . \\
\text { monococcum }\end{array}$ & $\begin{array}{c}T . \\
\text { dicoccum }\end{array}$ & $\begin{array}{c}T . \\
\text { durum }\end{array}$ & $\begin{array}{c}T . \\
\text { aestivum }\end{array}$ \\
\hline Present study & 1.00 & 1.76 & 1.91 & 2.30 \\
Rees (1965) & 1.00 & - & 1.80 & 2.58 \\
Upadhya and & 1.00 & 1.93 & 2.11 & 2.68 \\
Swaminathan (1963) & & & & (Chinese Spring) \\
& & & & 2.53 \\
& & & (C. 591) \\
\hline
\end{tabular}

Thus, it was found that of the two tetraploid species, $T$. durum has a higher DNA content than $T$. dicoccum and $T$. aestivum has a significantly greater amount of DNA compared to the tetraploid species. The estimates of DNA in the cells of different species can be used to find out whether the interspecies variation in this regard shows a correspondence with temperature sensitivity difference of chromosomes of four species, as measured by degeneration of the chromatin material. These differences in the sensitivity of the chromosomes of four varieties, on whose cells DNA estimates have been made, are presented in Table 2. The table shows that the diploid and hexaploid varieties differ greatly in the temperature sensitivity 
of their chromosomes. The difference between these two appears to be far more pronounced than the corresponding difference in their DNA content. Even more interesting is the observation that the chromosomes of the durum variety are more temperature sensitive than those of the dicoccum variety. In contrast to this, the DNA content as seen in Table 3 , is greater in the cells of the durum variety.

The above analysis, thus, shows that there is no simple relationship between the amount of DNA in the cells of the varieties of the different species, and the temperature sensitivity of their chromosomes. This finding provides support for the conclusion that chromosome doubling per se is not associated with greater environmental stability of the polyploid species, and that it is the production of a wide range of recombinants through hybridization and polyploidy, which has played an important role (Utkhede and Jain 1970).

\begin{abstract}
A number of diploid and polyploid species of wheat have been analysed for the sensitivity of their chromosomes to conditions of high temperature. A comparative estimate of deoxyribonucleic acid in the root-tip cells of different species has also been made by the autoradiographic technique. The diploid and hexaploid species differed greatly in temperature sensitivity of their chromosomes. The diploid, tetraploid and hexaploid species contained an increased amount of DNA in that order but the increase was not proportional to the chromosome number in these species. No simple correlation was found to exist between the amount of DNA in the cells of different species and the temperature sensitivity of their chromosomes.
\end{abstract}

\title{
References
}

Darlington, C. D. and LaCour, L. F. 1962. The Handling of Chromosomes. George Allen and Unwin Ltd. London.

Nishikawa, K. and Furuta, Y. 1969. DNA content per nucleus in relation to phylogeny of wheat and its relatives. Jap. J. Genet. 44: 23-29.

Pai, R. A., Upadhya, M. D., Bhaskaran, S. and Swaminathan, M. S. 1961. Chromosome diminution and evaluation of polyploid species in Triticum. Chromosoma 12: 398-409.

Rees, H. 1963. Deoxyribonucleic acid and the ancestry of wheat. Nature 198: 108-109.

Rees, H. and Walters, M. R. 1965. Nuclear DNA and the evolution of wheat. Heredity 20: 73-82.

Upadhya, M. D. and Swaminathan, M. S. 1963. Deoxyribonucleic acid and the ancestry of wheat. Nature 200: 713-714.

Utkhede, R. S. and Jain, H. K. 1970 . Contribution of different genomes to adaptability in wheat. Ind. J. Genet. and Pl. Breed 30: 451-461. 